RUUT VEENHOVEN

\title{
THE UTILITY OF HAPPINESS
}

(Received 10 April, 1987)

\begin{abstract}
The issue. Nineteenth century utilitarian philosophers considered happiness as the highest good ('utility' in their words) and claimed political priority for attempts to promote the greatest happiness for the greatest number. In reaction, many of their contemporaries cried out that happiness is not good at all, because it turns people into 'contented cows' and undermines social bonds. Modern psychologists, however, tend to suggest positive effects: sharper awareness, more activity, better social functioning and better health.

Data. No empirical investigations have yet focussed on consequences of happiness. Nevertheless, indications can be found in various studies covering other matters. This paper gathers the available data. These data do not allow definite conclusions, but do suggest several small yet noteworthy effects. Enjoyment of life seems to broaden perception, to encourage active involvement and thereby to foster political participation. It facilitates social contacts: in particular contacts with spouse and children. Further, happiness buffers stress, thereby preserving health and lengthening life somewhat. There is no evidence of harmful effects. It is concluded that society is more likely to flourish with happy citizens than with unhappy ones.
\end{abstract}

The study of happiness has long been the domain of moral philosophers. During recent decades social scientists have also taken an interest in the matter. Items on happiness now figure in quality-of-life surveys all over the world. Such investigations are meant to guide social policy. Levels of happiness are periodically assessed in order to make sure that no large scale discontent is brewing; the distribution of happiness is considered in order to identify social categories that need special care, and one tries to get an eye for determinants of happiness, hoping to find ways of improving happiness. Ideologically, this endeavour draws on the utilitarian creed that the ultimate political goal should be the promotion of the "greatest happiness for the greatest number", happiness gains being the yardstick of 'utility' of all actions. This 19th century moral philosophy is at the ideological basis of the 20th century welfare states which instigate quality-of-life research.

Though widely accepted, this ideology has not been left undiscussed. 
There are still many who consider happiness a mixed benefit and prefer to give priority to other values such as 'equality', 'solidarity' or 'salvation'. Some of these critics claim that the planned promotion of happiness will even be at the cost of such alternative values, and believe that it will lead to 'inequality', 'egoism' and 'sin'. Defense against such assaults requires empirically based knowledge about consequences of happiness. As long as such knowledge is lacking, current research on determinants of happiness is unlikely to influence social policy to any great extent. Even if it yielded usable proposals for enhancing the enjoyment of life, these proposals would probably not survive the debate of principle which would only then start in earnest.

As yet we know little about the consequences of happiness. Nothing has yet been published on the subject. Therefore this paper explores the field. It starts by considering current speculations about happiness consequences in more detail $(\$ 1)$. Next it takes stock of the available data sources that could be helpful in identifying consequences empirically $(\$ 2)$. With the help of these data a check of the reviewed speculations is attempted (\$3). Definite conclusions being unavailable in most cases, the paper closes with suggestions for further research $(\S 4)$.

In this paper 'happiness' or 'life-satisfaction' denotes the degree to which people judge the overall quality of their life as a whole favourably. Happiness in this sense is not the same as 'mental health', 'adjustment' or 'hope' (differences delineated in more detail in Veenhoven 1984: 32-36). The distinction with mental health is particularly relevant in this context. We know in fact quite a lot about the consequences of (bad) mental health. As mental health problems tend to go together with feelings of discomfort, consequences of mental dysfunctioning are often equated with consequences of unhappiness. The purpose of this paper is to consider possible independent effects of a positive or negative appreciation of life.

\section{SPECULATIVE VIEWS}

Though the matter has not yet been subject to systematic inquiry, some speculations have been thrown out. Negative effects have been claimed by 19 th century moral philosophers, while present-day psychologists have tended to stress positive effects. 


\section{The Negative View}

As noted above, negative effects have been stressed by opponents of the Utilitarian theory of value. Attacking its central doctrine, they argued that happiness is of no real benefit because it involves noxious side-effects. The arguments often mix up effects of 'happiness' with effects of 'hedonism'.

One of the harmful side-effects mentioned is that happiness will turn people into contented cows. Enjoyment of life would lead into idleness, discontent no longer stimulating the search for a better life. As a result creativity would falter and arts and sciences be drained.

This line of thought also predicts that pleasurable living will trample freedom. Smug contentment would benumb the outlook on the world, inducing a glassy and rosy view which ignores disturbing signs of suffering and danger. Happy citizens would therefore easily fall prey to political manipulation. Happiness-addicted people would be particularly dependent on the technocrats of hedonism in the service of the Utilitarian welfare state. It has also been suggested that happy-soft societies tend to be overrun by unhappy-hard hordes.

Another negative effect claimed is that happiness weakens social bonds, contentment leading to selfish individualism, because it results in self-conceit. Thus happiness would create a society of isolated egoists.

These views are presented literally in Aldous Huxley's Brave New World. They imply that a happy life does not bring out the best. Happy people thus make up an ugly society. Mild unhappiness would therefore be preferable.

\section{The Positive View}

Humanistic psychologists have on the other hand stressed the positive effects of enjoyment. Echoing early Greek eudaemonism, Maslow (1968) suggests that, together with 'joy' and 'peak-experiences', happiness accompanies growth towards 'self-actualization'. In his view happiness is both a result and an accelerator of growth. Contrary to the above mentioned critics of Utilitarianism, Maslow does not regard frustration as an indispensible impetus for action. He is rather sceptical of what he calls 'deficiency motivation' and expects humans to perform 
at their best when propelled by 'growth motivation': i.e. 'pulled' by pleasure instead of being 'pushed' by pain.

In opposition to anti-hedonistic sermons, Humanist psychologists associate happiness with 'zest' and believe that it stimulates activity and sharpens awareness. Effort and attention no longer being fixed on frustrations, human potential can be used to the fullest extent. Consequently it is thought that happiness accompanies creativity rather than kills it, since both proceed from the same psychological source and are thereby mutually stimulating.

In this view happiness facilitates social contacts, enjoyment freeing the way to authentic encounters, while unhappiness leads to preoccupation with oneself. The happy, growing individual is able to become involved in others, rather than using them for filling in the blanks. He is also more sensitive to other people's needs and emotions. These capacities are crucial in contacts with children: young children in particular. Poor relationship with parents can harm the mental health of children severely. In this line Fromm (1962: 49-50) claims that ". . a mother must not only be a 'good mother', but also a happy person".

A theme in current cognitive psychology is that positive self-attitudes work as a buffer to stress. A positive view of the world means that stressful life-events are perceived as challenges rather than as threats. Bad luck hurts less because one can draw on some emotional reserve. Protective effects of this kind are currently attributed to a high esteem of one's 'competence' in dealing with the problems of life and to perceived 'social support'. Incidentally they are associated with a positive appreciation of life-as-a-whole, or with mood level. The more one enjoys life, the better one can take knocks.

Finally, psycho-somatic theory holds that chronic frustration tends to increase vulnerability for disease. An implication of this view is that discontent with one's life-as-a-whole is likely to affect health negatively and that a positive appreciation of life will preserve good health.

Together these ideas suggest that humans function best when they take pleasure in life.

\section{STUDIES INDICATING EFFECTS OF HAPPINESS}

Empirical indications about the effects of a positive appreciation of life 
are scarce. With nobody having focused on the matter as yet, we must do with by-products of investigations which in essence centre on other subjects. The purpose of this paper is to take stock of the available indications.

\section{Relevant Investigations}

Life-satisfaction. In the first place, information can be drawn from studies aiming at determinants of life satisfaction. Most of these studies are correlational. Though these do not inform us about the direction of causality, they nevertheless suggest whether any causal effect is involved or not. No correlation being observed, an effect of happiness is unlikely to exist. In such cases it can only exist if counterbalanced by reverse effects or if suppressed by some spurious variable. Next to the hundreds of transversal correlational studies there is a handful of longitudinal ones. Most often these do not allow certainty about causality either, but they do provide at least stronger indications. For obvious reasons there are no experimental studies involving the manipulation of life satisfaction.

Mood. Indications about effects of happiness can also be drawn from the abundant studies on short term mood. Though being in a good mood is not the same as having a positive attitude towards life, the phenomena are closely linked. The more satisfied one is with life, the more often one is in a good mood. Two types of mood studies are of interest here:

Firstly, there are a lot of longitudinal studies on variations in behavior in pleasant, depressed and neutral mood. Most of these work with diary-like questionnaires. The analysis of these data tend to focus on behaviors that go with good mood rather than on behaviors that follow it. Therefore they do not give certainty about causality. Behaviors that are more frequently reported in moments of high mood can still be responsible for it rather than being its result. Pleasant mood may moreover induce more positive perceptions of otherwise similar behaviors.

Secondly, more definite conclusions can be drawn from experimental studies of mood. These involve the manipulation of mood through 
hypnosis, by having subjects read elated or depressed statements, or by exposing them to a cheerful or a sad movie. Yet an apparent limitation of such investigations is that they are rather distant from real life.

\section{Acceptable Indicators}

Various indicators of happiness are currently being used, some of which actually tap other things than the 'overall appreciation of life-asa-whole' at stake here. Therefore the investigations considered in this paper were screened. Investigations on life satisfaction were included only if measures fitted the demands I outlined elsewhere (Veenhoven, 1984: ch. 4). Several longitudinal geriatric studies involving so-called 'morale scales' were left out. Studies on short term mood were considered only to the extent that they concern overall pleasant or unpleasant affect. Studies on more specific affect states, such as 'anger' and 'aggression' were not included.

\section{SPECULATIONS CONSIDERED}

I will now inspect whether or not these limited data support the above mentioned theoretical speculations. The various - largely contradictory - claims are condensed in five issues. In succession I will consider whether happiness effects: (1) 'perceptiveness'; (2) 'activity'; (3) 'political participation'; (4) 'intimate ties'; and (5) 'health'.

In each case four types of evidence are considered: (1) I begin by setting the scene with a summary of the correlational findings on lifesatisfaction. (2) I next present in more detail relevant results from panel studies involving questions on life-satisfaction. (3) Then results of follow-up studies on transient mood and (4) finally experimental studies on mood. If one of these four types of studies is not mentioned in the discussion of an issue, I did not find any.

\subsection{Does Happiness Benumb?}

Hunches about happiness' effects on social perception are contradictory. As we have seen the negative view holds that happiness numbs, in particular that it limits awareness of suffering, injustice and danger. 
Happy people are said to smile while Rome burns. On the other hand, Humanist psychologists see happiness as accelerating mental growth and believe that it sharpens awareness and opens the way for concerns broader than one's own problems. In fact two related issues are at stake: whether happiness gives rise to an unrealistically rosy view of the world and whether it makes people less perceptive altogether.

Rosy look? Correlational studies show that happy people do indeed hold a rosier outlook. The happy are more satisfied with various aspects of life, they are more trustful of people in general and report more pleasant associations on tests (Data reviewed in Veenhoven, 1984: 343-352, 297-300. Few controls for spurious distortion).

Experimental mood studies suggest happiness causes rosiness. Hypnotically induced good mood elicits more pleasant reminiscences and a nicer view of other people (Bower, 1981).

Yet the fact that the cheerful are more inclined to see the good side of things does not imply that they perceive reality less accurately than the unhappy, who tend to see its gloomy sides. Correlational studies involving tests of defensiveness have not shown the happy to be more apt to fool themselves than the unhappy, though they appeared no less defensive either. In fact the happy were found to be somewhat more inclined to defensive 'reversal' and 'intellectualization', and the unhappy more apt to defensive 'projection'. No differences in 'repression' were found. It would not seem too difficult to check experimentally whether the happy view similar things less realistically than the unhappy. However, such experiments are not yet available. (There are experiments on the related issue of self-perception, which show 'depressives' to be more realistic than non-depressives. See Alloy and Abrahamson, 1979).

Less attentive? Correlational studies on life satisfaction have shown happy people to be more 'empathic' and 'socially sensitive'. This suggests more rather than less perceptiveness. The happy were also found to score slightly better on tests of cognitive 'field independence'. No differences appeared in 'conceptual differentiation' and 'categorization styles' or in 'test-intelligence'. Studies about concerns and interest show the happy to be more 'open to the world', more 'concerned with intimates and social problems' and less 'absorbed in personal problems'. 
This suggests a broader view (Research reviewed in Veenhoven, 1984: 279-281, 294-295, 309-315). None of these studies involved any control for spurious distortion, hence the observed lead of the happy may be due to associated factors such as 'personality' and 'education'.

Follow-up studies on mood also suggest sharper awareness: Observations of cognitive performance of the same persons in high and in low mood show for instance better performance on association tests in good moods (Dougan and Welch, 1984; Sullivan, 1922; Fisher and Marrow, 1934) or, at the worst, no difference (Johnson, 1937/8: 88). Likewise, thought is reported to be more fluent in good mood, and more oriented on the here-and-now. There is less tendency to take refuge in reminiscence in one's inner world (Wessman et al, 1960: 120). The notion that happiness desensitizes is supported only in Johnson's (1937/8: 94) finding that perceptual fluctuation on an ambigious figure test was lower in high mood.

To sum up: these data are clearly too limited to settle the issue definitively. For the time being it seems that happiness does give rise to a rosier look but not to a more hazy view.

\subsection{Does Happiness Lead into Idleness?}

Opinions differ about the effect of happiness on industry and activity. The negative view holds that people need the stick of discontent, whereas the positive view holds that it is the taste of the carrot that makes them move. This difference is not only of theoretical interest. If the negative view is correct, states had better not promote the happiness of their citizens, because that would reduce productivity and might thereby endanger national security in the long run.

Various correlational studies suggest that happiness leads to zestful activity rather than to contented passivity. First, levels of happiness and activity go hand in hand. The happy are for instance less often unemployed and more involved in unpaid tasks in clubs and churches. Moreover, the happy report greater leisure activity: they spend more time with friends, sports and hobbies. Happy people also feel more energetic than the unhappy. (Data reviewed in Veenhoven, 1984: 215$232,304-306)$. Similarly change in happiness goes with alteration of 
activity. In a 12-year follow-up study among Germans, decrease in mood appeared to be accompanied by a shrinking of both feelings of energy and actual activities. In their philosophy of life, the depressed were observed to stress the 'inevitability of suffering and confinement', whereas the cheerful rather talked about 'taking chances', 'meeting new people' and 'broadening interests' (Lehr, 1982: 245).

There is one longitudinal investigation on life-satisfaction that is of relevance to this issue. It is a one-year follow-up study among employed and unemployed persons in the Netherlands. Among the respondents unemployed at the first interview, the happy appeared more likely to have found a job by the time of the second interview. Among the respondents who had a job at the first interview, more of the unhappy had lost it a year later. Control for several potentially spurious variables reduced the differences but did not erase them (Verkley and Stolk, in print).

Follow-up studies on mood suggest an energizing effect of pleasant affect as well. Diary-studies found people feel more 'active' and 'energetic' when in high mood (Flügel, 1925: 345-6; Johnson, 1937/8: 192), and also consider the day more 'productive' (Hersey, 1932). Their response to frustration appeared more 'need-persistent' (Wessman et al., 1960: 130). People not only feel more energetic when cheerful, but they also behave more effectively. Hettema (1979) observed a 'better learning performance' of persons in high mood and Johnson (1937/8) found them more 'talkative' (p. 87) and to 'decide quicker' (p. 90). The latter investigator also observed more 'expansive writing movements' in high mood (p. 92), but observed no greater 'speed of association' on a word test (p. 88). Likewise, longitudinal investigations found pleasant affect predictive of 'training success'. Navy recruits who felt fine at the beginning of a 6-week strenuous physical training course performed better (Ryman et al., 1974: 482). Positive affect appeared also predictive of astronaut performance (Radlof and Helmreich, 1968). It is a pity that these latter studies have not been checked for potentially spurious variables, such as 'health' and 'motivation'.

Lastly, several experimental studies of mood indicate that high mood encourages activity. Brought into a high mood, people speak faster and more articulately (Trimboli, 1972; Natale, 1977), show more expansive writing movements (Strickland et al., 1974) and are more inclined to 
help others (i.a. Isen and Levin, 1972). As we have seen above, they also perform better on several cognitive tasks (Hale and Strickland, 1976; Fisher and Marrow, 1934).

To sum up: These pieces of evidence do not support the negative view of happiness fostering an apathetic letting go. On the contrary, they support the view that enjoyment of life opens the way to zestful involvement.

\subsection{Does Happiness Breed Voting Dummies?}

The difference in opinion on the effects of happiness on 'outlook' and 'activity' merge in conflicting views on its consequences for 'political vigilance'. The negative view in particular holds that happy ignorance together with contented idleness will result in easy conservatism and political apathy. Thus, happiness would lead to the emptying of democracy. If this view is correct, it would imply an incompability in the ideological program of present-day western welfare states, which try to promote both the personal happiness of their citizens and a general participation in democracy.

The evidence on this issue is restricted to correlational studies. Yet it is interesting enough.

Firstly, a lot of studies have considered whether discontent really is the driving force behind political participation. Contentment with various issues has been considered, amongst others 'satisfaction with one's self', 'acceptance of the political order' and 'appreciation of democracy'. Contented people did not appear to be underrepresented either in political movements or in parliaments (Data reviewed in Milbrath and Goel, 1977: ch. 3). Studies on extra-parliamentary political protest by means of riots, strikes and demonstrations do not show less involvement on the part of the satisfied either. Though political protest obviously draws on dissatisfaction with specific issues, activists are not typically frustrated or alienated. Next to specific discontent, political action depends on perceived chances and on the attribution of blame (Milbrath and Goel, 1977: ch. 3; Klandermans, in press).

Investigations on this matter involving measures of life satisfaction are less abundant and their results more mixed. The positive view is 
supported in the finding that happy people participate more in community organizations. It also links up with the earlier observation that the happy are more concerned with social and political problems. On the other hand, the negative view is confirmed in the fact that the happy are somewhat more inclined to maintain the political status quo and slightly less inclined to engage in boycotts, demonstrations and strikes (Research reviewed in Veenhoven, 1984: 328-9).

A study about public acceptance of the establishment of a nuclear plant in a US town compared the opinions of happy and unhappy neighbours. The happy did not differ from the unhappy in their 'perception of potential effects' and were no more 'accepting'. However, they appeared more 'consistent' in their stand, their acceptance corresponding more closely with their expectations (Lounsbury et al., 1979). This latter finding would suggest that the happy operate more rationally and are more able to meet the demands of democratic decision making, which assumes reasonable citizens.

To sum up: These findings do not suggest that happiness will drain democracy.

\subsection{Does Happiness Loosen Intimate Ties?}

Speculations about the effects of happiness on affiliation are diametrically opposed to one another: On the one hand, anti-hedonists claim that pleasy living will breed self-complacency and will thus loosen social bonds. Suffering would unite, whereas pleasure nuclearizes. On the other hand, Humanistic psychologists claim that happiness is part of a growth process that clears the way for 'true encounters'. Though unhappy frustrated people may be in greater need of love and friendship, they would be less able to establish lasting ties than happy selfactualizing individuals.

This broad issue can be split into four more specific questions: (1) Whether a positive appreciation of life drains affiliative motivation or fosters it; (2) Whether happiness hinders or facilitates contacts, especially contacts with children; (3) Whether it makes people appear more or less attractive to others; and (4) Whether the happy are actually more isolated socially or not; in particular whether they are more or less likely to find a spouse. 
Affiliative tendency. Correlational studies on happiness do not suggest that the happy turn up their noses at other people. They appear rather more concerned with others; the family stands more central in their aspirations and worries, and they adhere more to the "values of love and sympathy'. Happy people are also more 'satisfied with their friends and family' and show somewhat more 'trust in people in general' (Research reviewed in Veenhoven, 1984: 311-4, 322, 337-9. No control for spurious distortion).

There is only one longitudinal study of happiness. It involved a nineweek follow-up among recently divorced persons. During this period the originally most satisfied respondents did not distinguish themselves by a greater frequency of contacts (Sherman, 1979).

Observations on concomitants of good and bad moods show people to reach out more for contacts when they feel cheerful than when feeling down. In high mood they feel more inclined to engage in social contact' (Strickland and Hale, 1974). They feel both more 'positive to other people' and less 'threatened' (Johnson, 1937: 192; Borgatta, 1961). A person in a cheerful state of mind also feels more 'concerned about his peers' (Wessman and Ricks, 1966: 45) and is less inclined to 'react extra-punitively to frustration' (Kendall, 1954: 45; Wessman and Ricks, 1966: 45). Consequently people behave more 'generously' in high mood (Bryant, 1983).

In the same vein several experiments involving mood manipulation found induced positive mood to give rise to greater 'attraction-response to strangers' (Gouaux, 1971) and more inclination to 'help other people' (Various studies reviewed in Adermann, 1972). The happy appeared more helpful even when that was not to their advantage (Manucia et al., 1984). Yet two experiments involving mood manipulation by either a funny or a sad movie did not find a greater liking of others' among subjects in the cheerful condition (Gatley, 1969; Friedman et al., 1978).

Social ability. Correlational happiness studies found happy people to be more 'open', 'warm', 'facilitative' and 'empathic'. These findings link up with the often established fact that a positive appreciation of life goes together with less neurosis and with more psycho-social maturity (Research reviewed in Veenhoven, 1984: 275-6, 279-8. Little control for spuriousness). 
Studies of mood also suggest better social functioning in a cheerful state. As noted above, people tend to be more active and perceptive when feeling fine, and less hindered by anxiety and aggression. Depression is known to disorganize social behaviour to a great extent.

Quality of contacts with children. Several correlational studies indicate that happy parents get on better with their children than unhappy parents. Parents who abuse children appeared relatively unhappy (Dosch, 1979), and good contacts appeared more frequent among happy mothers (Henggeler and Borduin, 1981). Adolescent children of happy mothers more often claimed to be fond of them (Rose, 1955: 16). Similarly Crnic et al. (1983:214) found that the babies of unhappy mothers acted less cheerfully.

An experiment by Cohn and Tronick (1983) suggests that an effect of happiness is involved here, the unhappiness of parents distressing the child. Three-months old infants were filmed during three minute intervals of normal interaction and three minute intervals during which the mothers acted as though they were depressed. The babies reacted with negative facial expression of grimaces, crying and whimpering; even after the mother began to behave normally. The distress is not without reason: in low mood mothers got on less well with their children. Though they surveyed children more closely, they were less warm and involved and allowed the child less room for exploration. These findings link up with the clinical observation that genuinely depressed mothers tend to offer their children a hostile and rejecting home (Belsky, 1984: 85).

Attractiveness to others. Several experimental mood studies indicate that we prefer to socialize with happy rather than with unhappy persons.

One experiment observed reactions to people who differed in characteristic mood (Coyne, 1982). On the basis of standard tests, 30 American college women who generally felt depressed were selected. Each depressed woman was paired with one who usually did not feel depressed. For comparison, an equal number of non-depressed women was randomly paired with an other. All the couples were told that they were participating in a study about casual encounters and had to talk together to get acquainted. The participants then filled out a questionnaire about how willing they were to see their conversation partner 
again and how willing they thought their partner was to see her. Women who had chatted with a depressed partner appeared less willing than the controls to work with her again, ask her advice, sit next to her on a three-hour bustrip, or to invite her home. The depressed women appeared to expect such rejection. They were, in fact, more accurate in that than the non-depressed. In their turn, the depressed women were also less willing to have anything more to do with their partner.

Secondly, an experiment by Bell (1978) manipulated mood by having subjects read either a depressing story or funny cartoons. They were then told that the experiment was about how accurately one can judge others on the basis of very limited information. They were handed phoney person descriptions, varying in mood-profile (sad, neutral, happy) and were invited to indicate their liking for the persons concerned and their willingness to work with them. Subjects indicated greater liking for happy persons. Even unhappy subjects did so, in spite of their tendency to seek the company of like-minded.

Chance of marriage. Correlational studies show the happy to be more embedded in social networks. They have more contacts with family and friends and enjoy these more. Marriage is also more frequent among the happy and there is a close link between happiness and marital satisfaction (Research reviewed in Veenhoven, 1984: 232-58. Spurious distortion unlikely to be involved).

Two longitudinal studies in the USA suggest that happy people stand a better chance of marrying and are less likely to get divorced. In a twoyear follow-up investigation among recently divorced people, Spanier and Fürstenberg (1982: 718) found remarriage to be more frequent among the ones most happy at the first interview. Though indicative, this finding is not convincing, however. Many of the subjects who were remarried at the time of the second interview probably had already established a relationship with their partner at the time of the first interview and may have felt relatively happy for that reason. A five-year follow-up study by Erbes and Hedderson (1984) shows unhappiness to predict divorce. As divorce itself did not mark a further decrease in happiness and entering matrimony marked no increase, the investigators conclude that: "... psychological well-being affects marital status, rather than marital status affecting psychological well-being" (p. 937). Yet 
here again this conclusion is too hasty. Again, the possibility that marriage affects happiness rather than the reverse cannot be ruled out. The lower happiness of people who were to divorce a few years later can be a result of the marital problems they already experienced, divorce usually being preceded by years of muddling. In this light, it is not so remarkable that the actual break-up is not followed by a further decrease in happiness. As in the foregoing case, it is also comprehensible that entering into matrimony is not followed by a rise in happiness, the advantages of the bond with the spouse having taken effect long before the marriage ceremony.

Though direct evidence is scanty, it is nevertheless quite likely that happy people stand a better chance in marriage, particularly in modern western nations. Firstly, the happy are better endowed with qualities that are crucial in modern western love-marriage. As noted at the beginning of this paragraph, they have been observed to be more 'warm' and 'empathic', which is essential for the mutual understanding required in modern love. Secondly, the happy are also more 'assertive' and 'inner-controlled', which is an advantage as well, the interaction of spouses being increasingly less guided by convention and becoming more and more a matter of negotiation. Thirdly, happiness tends to foster 'self-esteem', which Fromm (1939) claims to be a prerequisite for giving and receiving love. Fourthly, unhappiness as such is likely to burden marriage. As marriage is currently seen as a main source of happiness, spouses are apt to think something is wrong in their relationship if one or both feel unhappy. Even if nothing is actually wrong with their marriage, such attributions may still shatter confidence and work as a self-fulfilling prophecy. Lastly, the unhappiness of one spouse burdens the other. This is shown in a firm correlation between the happinessratings of spouses (Rose, 1955: 16). The main rationale of modern marriage being to contribute to the happiness of both, it is not unlikely that marriage with an unhappy partner more often ends in divorce. These arguments are presented in more detail in Veenhoven 1987.

To sum up: there are no indications that happiness loosens social bonds. The data rather suggest that happiness facilitates affiliation and strengthens intimate ties. Strict proof of causality is not yet available, however. 


\subsection{Is Happiness Healthy?}

Three positive effects have been suggested, which can all be linked with the concept of 'stress'. In the psycho-somatic view, unhappiness is a source of stress itself, which in some way increases liability to disease. In the cognitive view, happiness moderates the impact of healththreatening life-events. A happy person is thought to be less hurt than an unhappy one by the same event, his positive appreciation of life modifying perception. In the Humanistic line of thought one could further theorize that beneficial effects of happiness on mental 'growth' enhance psychological effectiveness and thus allow a better coping ability. Unlike the foregoing issues, the reverse has not been claimed by anti-hedonists.

Buffer to stress. Correlational studies have shown less stress among the happy: fewer reports of unpleasant life-events, less worries and less psycho-somatic complaints, such as insomnia and headaches (Research reviewed in Veenhoven, 1984: 269-70, 314, 367-8. Few controls for spurious distortion).

Two follow-up studies involving assessments of current mood found the originally most cheerful respondents to report less unpleasant events later on and more positive ones (Lewinsohn, 1975 over a 30day period, and Heady et al., 1984: 216 over a two-year period). Yet Clark (1977) found no difference.

To a great extent this is a matter of perception; similar events are depicted as pleasant by the happy, but as unpleasant by the unhappy. Estimates of their frequency are also distorted by mood (Demonstrated experimentally by Buchwald, 1977). Yet the possibility remains that the happy are really luckier as well, possibly because they are nicer people (Suggested by Heady et al. 1984:218).

One longitudinal study shows a similar unpleasant event hurting the happy less than the unhappy. In the earlier cited follow-up study in the Netherlands of Verkley and Stolk (in press), the originally most happy respondents were found to cope better with continued unemployment. They showed less increase in psycho-somatic complaints one year later than the unemployed respondents who claimed to be unhappy at the first interview. 
Susceptibility to disease. Correlational studies of life-satisfaction show better health among the happy, far better self-rated health and slightly better health-status as assessed by physicians. (Research reviewed in Veenhoven, 1984: 268-72. Distortion unlikely to be involved)

A longitudinal study demonstrated that this difference is at least partly due to an effect of happiness on health. Low mood was shown to be followed by an increase in somatic complaints three months later (Brenner, 1979). This result links up with the observed negative effects on physical health of depression (Lieberman and Miller, 1965).

Longevity. No less than ten longitudinal studies have questioned elderly people about their life satisfaction and then followed them until death (Bond, 1983; Botwinnick et al., 1978; Deeg, 1986; Janoff-Bulman and Marshall, 1982; Kaplan and Camadro, 1983; Lehr et al., 1974, 1983; Palmore, 1974; Palmore et al., 1976; Zuckerman et al., 1984). One found no difference (Palmore et al., 1976) and one found the happy to pass away earlier (Janoff-Bulman and Marshall, 1982). This latter study was among elderly persons admitted to a nursing home. The ones most happy at the interview were at that moment less apt to accept the fact that they were never to leave the institution and still hoped to recover.

The eight other studies observed the happy to live longer. This result may be due to effects of factors associated with happiness rather than to the effect of happiness as such. In particular, the physical and mental health of the happy could be responsible for their longer survival. Therefore, five studies performed statistical controls. This reduced the difference considerably: in two studies it was reduced to insignificance (Botwinnick et al., 1978; Kaplan and Camadro, 1983), whereas in the other three cases small significant effects remained (Deeg, 1986; Palmore, 1974; Zuckerman et al., 1984).

To sum up: these studies demonstrate that a positive appreciation of life tends to affect health positively, though not very strongly.

\section{FURTHER RESEARCH}

This exploration allows no firm conclusions in any of the issues considered. Tracing down causality requires methodologically better 
studies, particularly panel-studies covering large time spans. The design of such studies should allow control for spurious distortions in order to distinguish the effects of happiness from those of associated variables, such as 'mental health' and 'social support'.

Investigations of the required kind are costly, because they must involve many variables and repeated interviews. Fortunately, we really do not need any special investigations. We can learn a lot by including the matter in studies centering on other questions. Studies quite suited to that purpose are longitudinal quality-of-life studies, aiming in the first place at the identification of determinants of happiness. At this moment several large-scale panel studies are being carried out, i.a. in Germany (Lehr and Thomae: Krupp), and Australia (Heady and Wearing). It will be worthwhile to analyse their results from the other point of view. It would also pay to re-analyse various geriatric follow-up studies that have been performed. The available reports are of little use, because they hardly consider the consequences of happiness and also because they use too broad 'morale scales'. Yet most data-sets do involve acceptable indicators of happiness, hence secondary analysis can yield useful information. In the longer run it would be useful to include items on happiness in long term developmental studies, especially in investigations that start in early adolescence, when attitudes towards life take shape. Such studies not only cover greater time-spans than quality-oflife panels usually do, but they also contain more varied information about personality and mental health, thereby allowing more opportunity to sift out pure effects of the enjoyment of life.

Three things should be kept in mind when analysing such data: Firstly it is advisable not to focus too closely on 'the' effects of happiness, but to keep an open eye for contextual variations. I suggested above that the better marriage chances of the happy will be less pronounced in a traditional marriage pattern. Likewise, one could imagine that the effects of happiness on productivity are greater in jobs allowing self-direction, and that consequences of happiness for health and longevity are most pronounced in hedonistically orientated cultures. Secondly, one should keep in mind the possibility that zeroresults mask opposed effects. Unhappiness could foster political participation among competent people but paralyze incompetent ones for example. A final and most difficult problem is that control for spurious 
effects may wash away real but indirect effects, for instance control for 'mental health' in survival studies may give rise to an underestimation of the effect of happiness, because happiness is likely to determine mental health to some extent.

\section{CONCLUSION}

Happiness is seen to have its consequences. Though absolute certainty is still out of reach, there are indications of several modest effects. Contrary to anti-hedonistic preaching, these effects are not harmful. Happiness does not lead to rosy passivity or self-complacent egoism. Rather, enjoyment of living stimulates active involvement and encourages social contacts. It also preserves health and tends to lengthen life slightly.

Society is therefore likely to flourish to a greater extent with happy citizens than with unhappy ones. Politically, because happy citizens are not less critical, but on the contrary are rather more concerned about social problems and more consistent in their stand. Economically, because happy citizens tend to be more healthy and hard working. Socially, because happy citizens weave closer intimate networks and provide their children with warmer homes, thus laying the basis for a sane society.

\section{REFERENCES}

Adermann, D. Elation: 1972, 'Depression and helping behavior', Journal of Personality and Social Psychology 24, 91-101.

Alloy, L. B. and Abrahamson, L. Y.: 1979, 'Judgement of contingency in depressed and non-depressed students. Sadder but wiser?', Journal of Experimental Psychology $168,441-485$.

Bell, P.: 1978, 'Affective state, attraction, and affiliation: Misery loves happy company too', Personality and Social Psychology Bulletin 4, 616-619.

Belsky, J.: 1984, 'The determinants of parenting - a process model', Child Development 55, 83-96.

Bond, J. B.: 1983, 'A non-medical approach to the prediction of distance from death', Paper presented at the 7 th ann. meeting of the Canadian Ass. of Gerontology Moncton.

Borgatta, E. F.: 1961, 'Mood, personality and interaction', Journal of General Psychology $64,105-137$.

Botwinnick, J., West, R., and Storandt, M.: 1978, Predicting death from behavioral test performance', Journal of Gerontology 33, 755-762. 
Bower, G. H.: 1981, 'Mood and memory', American Psychologist 36, 129-148.

Brenner, B.: 1979, 'Depressed affect as a cause of associated somatic problems', Psychological Medicine 9, 737-746.

Bryant, B. K.: 1983, 'Context of success: Affective aroused generosity', American Educational Research Journal 20, 553-562.

Buchwald, A. M.: 1977, 'Depressive mood and estimates of reinforcement frequency', Journal of Abnormal Psychology 86, 443-446.

Clark, J. C. V.: 1977, 'Outcome and adjustment in untreated mild depression', Unpubl. Ph.D. dissertation, University of Oregon.

Cohn, J. and Tronick, E.: 1983, 'Three-month-old infants' reaction to simulated maternal depression', Child Development 54, no. 1.

Coyne, J.: 1982, 'Shunning the depressed', Psychology Today, March, 80-81.

Crnic, V. A., Greenberg, M. T., Ragezin, Z. S., Robinson, N. M., and Bosham, R. B.: 1983 , 'Effects of stress and social support on mothers and premature and full term infants', Child Development 54, 209-217.

Deeg, D.: 1987, 'En ze leefden nog lang en gelukkig: Satisfactie als predictor voor overlevingsduur bij bejaarden', Gezondheid en Samenleving 7, 98-107.

Dosch, M. F.: 1979, 'Child abuse: A comparison of physical abuses, sexual abuses and non-abuses on perceived locus of control, self acceptance and avowed happiness', Unpubl. Ph.D. diss. University of Oregon, U.S.A.

Dougan, C. and Welch, L.: 1948, 'A study of elation, making use of the Rorschach test and associated tests', Journal of Psychology 20, 363-366.

Erbes, J. T. and Hedderson, J. J. C.: 1984, 'A longitudinal examination of the separation/divorce process', Journal of Marriage and the Family, Nov., 937-941.

Fisher, V. E. and Marrow, A. J.: 1934, 'Experimental study of moods', Character and Personality $2,201-209$.

Flügel, J. C.: 1925, 'A quantitative study of feeling emotion in everyday life', British Journal of Psychology 15, 318-355.

Friedman, H. S., Rubin, Z., Jacobson, J., and Clare, G.: 1978, 'Induced affect and attraction towards dating partners and opposite sex strangers', Social Psychology 9, $57-63$.

Fromm, E.: 1939, 'Selfishness and self-love', Psychiatry 2, 507-523.

Fromm, E.: 1962, The Art of Loving, Harper \& Row, New York.

Gatley, R. H.: 1969, 'Happiness and affiliation', Unpubl. paper. Mich. State Univers.

Gouaux, C.: 1971, 'Induced affective state and interpersonal attraction', Journal of Personality and Social Psychology 20,37-43.

Hale, W. D. and Strickland, B. R.: 1976, 'Induction of mood states and their effects on cognitive and social behaviors', Consulting and Clinical Psychology 44, 153.

Heady, B., Holmström, E., and Wearing, A.: 1984, 'The impact of life events and changes in domain satisfactions on well-being', Social Indicators Research 15, no. 3, $203-227$.

Henggeler, S. W. and Borduin, C. M.: 1981, 'Satisfied working mothers and their preschool sons: Interaction and psycho-social adjustment', Journal of Family Issues $2,322-325$.

Hersey, R. B.: 1932, Workers' Emotions in Shop and Home - A Study of Individual Workers from the Psychological and Physiological Standpoint, University of Pennsylvania Press, Philadelphia, U.S.A.

Hettema, C. M.: 1979, 'Effects of mood on recall of pleasantly and unpleasantly rated scentences', Unpubl. Ph.D. diss, Fordham Univers. U.S.A.

Huxley, A.: 1932, Brave New World, Continental Book Co., Stockholm.

Isen, A. M. and Levin, P. F.: 1972, 'The effect of feeling on good-helping cookies and kindness', Journal of Personality and Social Psychology 21, 384-388.

Janoff-Bulman, R. and Marshall, G.: 1982, 'Mortality, well-being and control', Personality and Social Psychological bulletin 8, 691-698. 
Johnson, W. B.: 1937, 'Euphoric and depressed moods in normal subjects I \& II', Journal of Character and Personality 6, 79-98.

Kaplan, G. A. and Camandro, T.: 1983, 'Perceived health and mortality: A nine-year follow-up of the Human Population Laboratory Control', American Journal of Epidemiology 117, 292-304.

Kendall, P.: 1954, Conflict and Mood, The Free Press, Glencoe, Ill. U.S.A.

Klandermans, B.: 'Ongeluk maakt niet opstandig: De complexe relatie tussen ontevredenheid en protest', in R. Veenhoven (ed.), The wages of satisfaction (in preparation).

Lehr, N. M.: 1982, 'Depression und Lebensqualität im Alter: Korrelate negativer und positiver Gestimmtheit', Zeitschrift für Gerontologie 15, 241-249.

Lehr, U. and Schmitz-Scherer, R.: 1974, 'Psycho-soziale Korrelate der Langlebigkeit', Aktuelle Gerontologie 4, 261-268.

Lehr, U., Schmits-Scherer, R., and Zimmerman, E.: 1983, Sozial-psychologische Korrelate der Langlebigkeit, Universität Bonn, Psychologisches Institut.

Lewinsohn, P. M.: 1975, 'The behavioral study and treatment of depression', in M. Hersen, R. M. Eisler, and P. M. Miller (eds.), Progress in Behavior Modification, Vol. 1, Academic Press, New York, U.S.A.

Looker, Y. B.: 1981, 'Maternal mood and mother-child attachment behavior', Unpubl. Ph.D. diss. Columbia University, U.S.A.

Lounsbury, J. W., Sundstrom, E., and Shields, M.: 1979, 'The relationship of avowed life satisfaction to public acceptance of and expectations about a nuclear powerplant', Journal of Community Psychology 7, 298-304.

Manucia, G. K., Bauman, D. J., and Cialdini, R. B.: 1984, 'Mood influences of helping: direct effects or side effects?', Journal of Personality and Social Psychology 46, 357-364.

Maslow, A. H.: 1968, Towards a Psychology of Being, Nostrand, New York, U.S.A.

Milbrath, L. W. and Goel, M. L.: 1977, Political Participation, Rand McNally College Publishing Company, Chicago, U.S.A.

Miller, D. and Liebermann, M. A.: 1965, 'The relationship of affect state and adaptive capacity to reaction to stress', Journal of Gerontology 20, 492-497.

Natale, M.: 1977, 'Effects of induced elation-depression on speech in initial interview', Journal of Consulting and Clinical Psychology 45, 45-54.

Palmore, E.: 1974, 'Predicting longevity; A new method', in Palmore, E. (ed.), Normal Aging II, Report from Duke longitudinal Studies 1970-1975, Duke University Press, Durham NC, U.S.A.

Palmore, E. and Cleveland, W.: 1976, 'Aeging, terminal decline and terminal drop', Journal of Gerontology 31, 76-81.

Radloff, R. and Helmreich, R.: 1968, 'Groups under stress: Psychological research in Sealab II', Appleton-Century-Crofts, New York, U.S.A.

Rose, A. M.: 1955, 'Factors associated with the life satisfaction of middle-class, middle aged persons', Marriage and Family Living 17, 15-19.

Ryman, D. H., Biersner, R. J., and LaRocco, J. M.: 1974, 'Reliabilities and validities of the mood questionnaire', Psychological Reports 35, 479-484.

Sherman, L. K.: 1979, 'The correlates of happiness in post-separation adjustment', Unpubl. Ph.D. diss. University of Oregon, U.S.A.

Spanier, G. B. and Fürstenberg, F. F.: 1982, 'Remarriage after divorce: A longitudinal analysis of well-being', Journal of Marriage and the Family, Aug., 709-720.

Strickland, B. R. and Hale, W. D.: 1974, 'Effect of induced mood states on activity and self reported affect,' Paper presented at the 82th Am. Psych. Conv., New Orleans.

Sullivan, E. T.: 1922, 'Mood in relation to performance', Archives of Psychology 8, nr. 53.

Trimboli, F.: 1972, 'Changes in voice characteristics as a function of trait and state personality variables', Unpubl. diss. Ohio University. 
Veenhoven, R.: 1984, 'Conditions of Happiness', Reidel Publ. Co., Dordrecht, The Netherlands.

Veenhoven, R.: 1987, 'Alleen leven en geluk' (Single living and happiness), Gedrag en Gezondheid 15, 107-117.

Veenhoven, R. (ed.): in preparation, 'The wages of satisfaction'.

Verkley, H. and Stolk, A.: 'De invloed van geluksgevoelens op werkloosheid', in R. Veenhoven (ed.), 'The wages of satisfaction' (in preparation).

Wessman, A. E. and Ricks, D. T.: 1966, Mood and Personality, Holt, Rinehart \& Winston, New York.

Wessman, A. E., Ricks, D. F., and Tyl, M. M.: 1960, 'Characteristics and concomittants of mood fluctuation in college women', Journal of Abnormal Social Psychology, Jan., 117-126.

Zuckerman, D. M., Kasl, S. V., and Ostfeld, A. M.: 1984, 'Psychological predictors of mortality among the elderly poor. The role of religion, well-being and social contacts', American Journal of Epidemiology 119, 410-423.

Social Sciences Department,

Erasmus University,

Postbus 1738,

3000 DR Rotterdam,

The Netherlands. 